Article

\title{
Effects of Lake-Reservoir Pumped-Storage Operations on Temperature and Water Quality
}

\author{
Ulrike Gabriele Kobler $^{1, *(1)}$, Alfred Wüest ${ }^{1,2 \text { (i) }}$ and Martin Schmid ${ }^{1(1)}$ \\ 1 Eawag, Swiss Federal Institute of Aquatic Science and Technology, Surface Waters-Research and \\ Management, CH-6047 Kastanienbaum, Switzerland; alfred.wueest@eawag.ch (A.W.); \\ martin.schmid@eawag.ch (M.S.) \\ 2 EPFL, Physics of Aquatic Systems Laboratory-Margaretha Kamprad Chair, ENAC-IEE-APHYS, \\ CH-1015 Lausanne, Switzerland \\ * Correspondence: ulrike.kobler@eawag.ch
}

Received: 14 May 2018; Accepted: 8 June 2018; Published: 12 June 2018

\begin{abstract}
Pumped-storage (PS) hydropower plants are expected to make an important contribution to energy storage in the next decades with growing market shares of new renewable electricity. PS operations affect the water quality of the connected water bodies by exchanging water between them but also by deep water withdrawal from the upper water body. Here, we assess the importance of these two processes in the context of recommissioning a PS hydropower plant by simulating different scenarios with the numerical hydrodynamic and water quality model CE-QUAL-W2. For extended PS operations, the results show significant impacts of the water exchange between the two water bodies on the seasonal dynamics of temperatures, stratification, nutrients, and ice cover, especially in the smaller upper reservoir. Deep water withdrawal was shown to strongly decrease the strength of summer stratification in the upper reservoir, shortening its duration by $\sim 1.5$ months, consequently improving oxygen availability, and reducing the accumulation of nutrients in the hypolimnion. These findings highlight the importance of assessing the effects of different options for water withdrawal depths in the design of PS hydropower plants, as well as the relevance of defining a reference state when a PS facility is to be recommissioned.
\end{abstract}

Keywords: hydropower; stratification; reservoir modeling; recommissioning

\section{Introduction}

The share of "new renewables", such as photovoltaic and wind power plants, to the electricity production is increasing globally as a consequence of political decisions to reduce greenhouse gas emissions [1,2]. At the end of 2016, $2017 \mathrm{GW}$ of renewable power capacity were installed globally [3], with parts of $\sim 300 \mathrm{GW}$ and $\sim 490 \mathrm{GW}$ from photovoltaic and wind power, respectively. The integration of these "new renewables" to the electrical grid is challenging due to their intermittency [4] and entails network load stability problems resulting from decentralized production [5]. Electricity storage addresses a large part of these timing and stability issues.

Even today, the most efficient technologies for storing electric energy are still pumped-storage (PS) hydropower plants, which also provide ancillary services such as voltage support and various forms of reserve capacity to fine-tune the matching of supply and demand and to ensure reliability [3]. Worldwide, $>300$ PS hydropower plants were installed with a total capacity of $\sim 150 \mathrm{GW}$ by the end of 2016, and plans existed for another $40 \mathrm{GW}$ by 2020 [3], with overall energy efficiencies reaching up to $87 \%$ and an individual size of up to $3000 \mathrm{MW}$ [6]. Thus, within the last few years, PS operations regained attention, and overviews of proposed PS hydropower plants have been presented in various studies $[1,7]$. 
However, PS operations modify physical and geochemical (abiotic) as well as ecological (biotic) properties of the connected water bodies. Abiotic effects include changes of water temperature, stratification, water level fluctuations, sediment resuspension, oxygen and nutrient cycling in the water column as well as modifications of inorganic suspended sediment, which accordingly alter light penetration [8]. Additionally, lake-internal circulation patterns [9] as well as ice cover [10,11] may be affected.

Biotic PS impacts are, in general, less studied but can include effects such as stranding of juvenile fish in littoral zones during dewatering [12], entrainment of organisms [13], and spreading of alien species from downstream to upstream [14].

Assessing PS impacts for different scenarios is typically undertaken by the application of numerical models. Models of different complexity have previously been applied for studying impacts of reservoir management on water quality. These range from one-dimensional models such as GLM-AED [15], DYRESM-CAEDYM [16] or MyLake [17], to three-dimensional models such as the Environmental Fluid Dynamics Code [18], Delft3D [19] or ELCOM-CAEDYM [16,20]. Models of lower complexity have the advantage of shorter computation times, allowing for large numbers of simulations, e.g., for the purpose of parameter estimation or scenario simulations, but may not be able to adequately reproduce the effects of local inflows on basin-scale dynamics and water quality, especially for large local discharges as they are typically introduced by PS operations. Three-dimensional models can resolve these spatial dynamics, but their computational demand, especially when coupled to water quality models, still precludes their application to long-term studies and for purposes where a large number of simulations is required. Furthermore, spatially resolved observational data are often not available to calibrate the three-dimensional processes.

For our case, the simulation of a coupled lake-reservoir system over a time scale of 15 years and with a potential future application to climate change scenarios, the two-dimensional, laterally averaged hydrodynamic and water quality model CE-QUAL-W2 is a good compromise between spatial resolution and computational demand. It has previously been applied to numerous case studies for reservoir management [21,22], among which also another case study of a lake and a reservoir coupled by PS [23].

When planning a new or extending an existing PS scheme, environmental effects need to be projected and minimized during the planning phase [14,24]. For this purpose, a reference state needs to be defined. This could be the natural state without a reservoir. However, in the case of existing reservoirs, which are often used for multiple purposes, such as for flood protection and recreation [14], reservoir removal could have relevant ecological and socio-economic effects, and might therefore not be a realistic option [25]. Hence, other artificial reference states can be considered to analyze the impacts of PS extension or for recommissioning present PS operation.

This study aimed to assess the impacts on temperature, stratification as well as water quality in a natural lake and a reservoir connected by a PS hydropower plant. We analyzed: (a) its extension; and (b) two reference scenarios without PS operation. Both reference scenarios keep the dam, but they differ in withdrawal depth of the outflow which either remains at the current depth of the residual flow outlet in the hypolimnion or is moved up to the surface. The first reference scenario allowed individually assessing the impacts of water exchange due to PS, while the second corresponded to a "quasi-natural" behavior of the reservoir. We hypothesized that the impacts of PS operations are partially caused by the exchange of water between the two water bodies, and partially by the depth of water removal from the upper reservoir. To disentangle these effects, the scenarios were simulated using the 2D-model CE-QUAL-W2 and compared to the present PS operation.

\section{Study Site}

Etzelwerk, a PS hydropower plant located in Switzerland, was chosen as the study site. It was built in the 1930s and is operated between Sihlsee and Upper Lake Zurich (Figure 1). Its current concession runs out at the end of 2022. For its renewal, several options for extending the PS operation 
have been considered: 525 (265) MW, 250 (80) MW and 150 (60) MW for the generating (pumping) mode. Additionally, a reference state was defined as a base for the required mitigation measures.

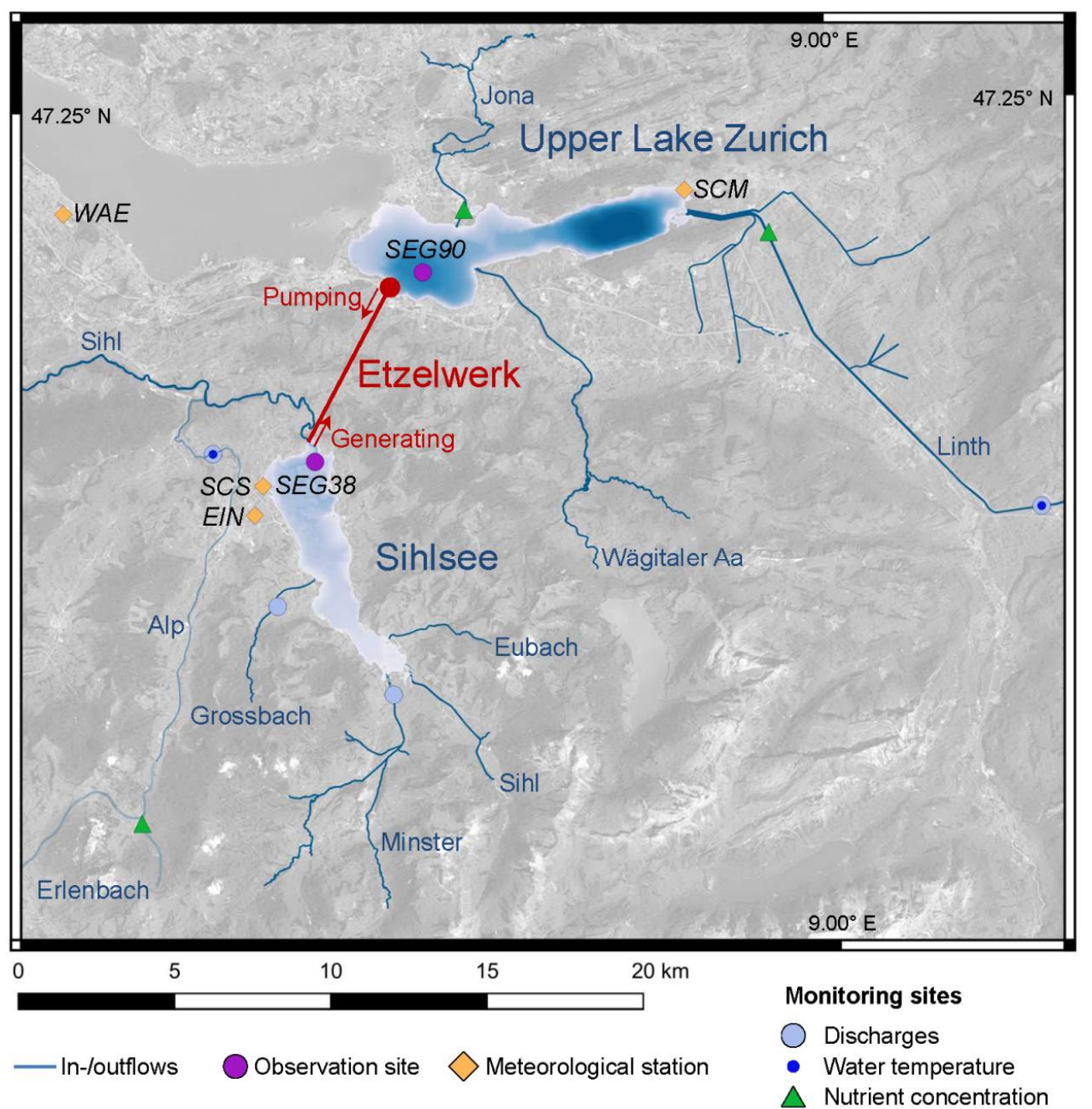

Figure 1. Overview of study site: Etzelwerk with its two connected water bodies Sihlsee (upper reservoir; $8.5 \mathrm{~km}$ long and $2.5 \mathrm{~km}$ wide) and Upper Lake Zurich (lower lake; $10.5 \mathrm{~km}$ long and $2.5 \mathrm{~km}$ wide). Meteorological stations refer to: EIN: Einsiedeln; WAE: Wädenswil; SCM: Schmerikon (all MeteoSwiss); and SCS: Segelclub Sihlsee. The MeteoSwiss station at Zurich Fluntern (SMA) is outside the graph (coordinates: $8.56573^{\circ} \mathrm{E}, 47.37789^{\circ} \mathrm{N}$ ). Observation sites correspond with the deepest points of model segments 38 (SEG38) and 90 (SEG90), for which model results were generated.

Sihlsee is the artificial upper reservoir of the Etzelwerk PS hydropower plant (Figure 1). At maximum water level, it is $23 \mathrm{~m}$ deep, has a surface area of $11.3 \mathrm{~km}^{2}$ and a volume of $96.1 \times 10^{6} \mathrm{~m}^{3}$. The water level varies by $12.5 \mathrm{~m}$ between 889.34 and $876.84 \mathrm{~m}$ a.s.l., thus the storage capacity is $\sim 89.4 \times 10^{6} \mathrm{~m}^{3}$. The catchment area is $156.5 \mathrm{~km}^{2}$, with the major tributaries Minster (40\% of catchment), Sihl (21\%), Grossbach (7\%) and Eubach (6\%). The grid location of inflows, outflows and PS flows is depicted in Figure A1 of Supplementary Material S1. The current hydraulic residence time is $\sim 135$ days. Since no previous observations were available, temperature, oxygen and nutrient concentrations were monitored in Sihlsee during 2014-2016 as a base for model calibration. The observations were made at SEG38 and are summarized in Supplementary Material S1 (Section B).

Upper Lake Zurich is the lower lake of this PS hydropower plant and is of natural origin (Figure 1). Its surface elevation varies by $\sim 1.0 \mathrm{~m}$ between 405.5 and $406.5 \mathrm{~m}$ a.s.l. At highest water level, it has a maximum depth of $48 \mathrm{~m}$, a surface area of $20.25 \mathrm{~km}^{2}$ and a volume of $470 \times 10^{6} \mathrm{~m}^{3}$. The catchment 
area $\left(1564 \mathrm{~km}^{2}\right)$ is about one order of magnitude larger than that of Sihlsee. The main tributaries contributing to this catchment are Linth ( $83 \%$, including the discharge from Walensee and Linthebene), Jona ( $5 \%)$ and Wägitaler Aa ( $5 \%)$. The average water residence time is $\sim 70$ days. Additional information on bathymetry and model forcing can be found in Supplementary Material S1 (Section A), and an overview of the physical and chemical properties of Upper Lake Zurich (monitored by a routine program at SEG90) is given in Supplementary Material S1 (Section B).

Epilimnion temperatures at both lakes are rather similar. Hypolimnion temperatures at Sihlsee can reach up to $<17^{\circ} \mathrm{C}$ in summer, whereas those at Upper Lake Zurich remain below $6{ }^{\circ} \mathrm{C}$. During the stagnation phase, suboxic or anoxic conditions develop in the hypolimnia of both lakes. Mean annual nitrate concentrations differ significantly between Sihlsee $\left(\sim 230 \mu \mathrm{g} \mathrm{N} \mathrm{L}^{-1}\right)$ and Upper Lake Zurich $\left(\sim 660 \mu \mathrm{g} \mathrm{N} \mathrm{L}^{-1}\right)$, respectively, while mean total phosphorus concentrations are similar in both water bodies, even though higher peak concentrations are reached in Sihlsee after flood events.

The average annual water balances (calculated for the period 1997-2015) of both water basins are given in Table 1. The extended PS operation would increase the water exchange between the two water bodies from 214 to $778 \mathrm{~m}^{3} \mathrm{~s}^{-1}$ for the PS generating flow and from 26 to $590 \mathrm{~m}^{3} \mathrm{~s}^{-1}$ for the PS pumping flow (Table 1). The seasonality of the artificial PS flows is shown in Figure A2 of Supplementary Material S1. For both reference scenarios, no PS flows were considered. The hydraulic residence time of Sihlsee is, therefore, increased to $\sim 150$ days in both reference scenarios and reduced to $\sim 40$ days in the extended PS scenario.

Table 1. Annual water balance of the two water bodies of Etzelwerk. Sum of all inflows, outflows and artificial flows for present and extended PS operation as well as for the two reference scenarios NoPS and QNat (details given in Section 3.2). A correction term was required to close the water balance for Sihlsee, described in Supplementary Material S1 (Section A.3).

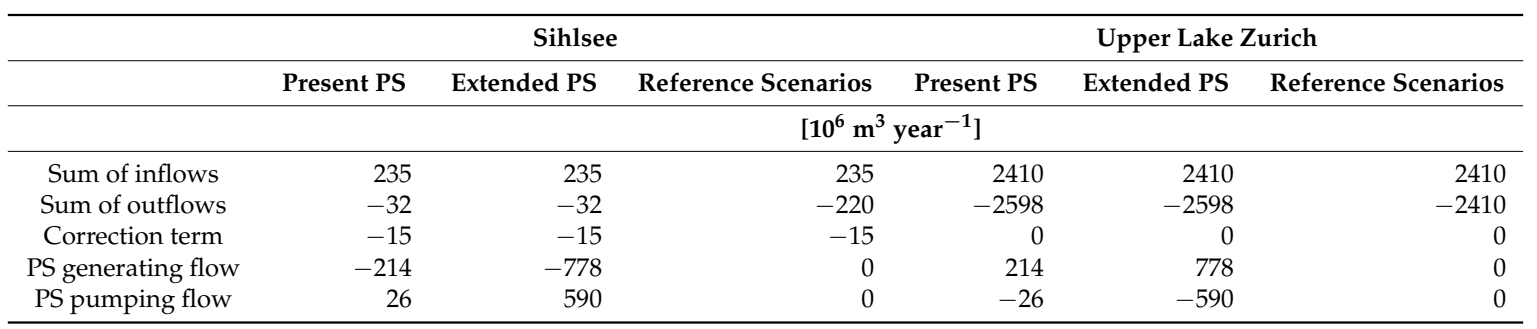

\section{Materials and Methods}

\subsection{Model Description}

The simulations were run with the model CE-QUAL-W2, version 3.71 [26], developed in a cooperation of the US Corps of Engineers and the Portland State University. It is a two-dimensional laterally averaged hydrodynamic and water quality model. The two water bodies are directly connected in the model, i.e., the volumes of head race tunnel and penstock are neglected. In effect, this volume needs to be flushed at every PS flow inversion before water is effectively transferred between the two water bodies. For the present PS, this accounts for $\sim 5 \%$ and $\sim 13 \%$ of the generating and pumping flows, respectively. Thus, the volume exchanged between the two water bodies is slightly overestimated. Frictional losses were considered, with an assumption of $90 \%$ and $80 \%$ efficiency level for generating and pumping, respectively. The effect of this frictional warming was, however, minor.

The model forcing includes meteorological, hydrological and water quality forcing as well as bathymetrical data. A detailed description including initial conditions is given in Supplementary Material S1 (Section A). All simulations were run for the period 1997-2012, whereas years 2013-2015 and 1998-2015 were used for calibration of Sihlsee and Upper Lake Zurich, respectively. The first year of each period was considered as spin-up phase, and not included in the results. The results shown for Sihlsee were generated at model segment 38 (SEG38), and those for Upper Lake Zurich at model 
segment 90 (SEG90) (Figure 1). These segments correspond to the observation locations at the two water bodies. A detailed description of the PS scenarios follows in Section 3.2.

The model considered an hourly time step and the model variables comprise: water temperature, dissolved oxygen, inorganic suspended solids, phosphate, ammonium, sum of nitrate and nitrite, dissolved and particulate organic matter (labile and refractory), algae (two groups) and zooplankton.

The model was calibrated against observations through a manual trial and error calibration. Parameter values were either set according to recommendations from literature or tuned to match observations (details in Supplementary Material S1: Section B). The identified parameter set, the comparison between observed and simulated profiles and time series as well as the computed mean absolute error (MAE) and mean error (ME) of temperature, dissolved oxygen, total phosphorus and the sum of nitrate and nitrite are given in Supplementary Material S1 (Section B.2).

The root mean square errors (RMSEs) for the entire calibration period for the overall water column, the epilimnion and the hypolimnion are shown in Table 2. The RMSE of temperature is $<1^{\circ} \mathrm{C}$ for both water bodies, which is comparable to the range of $\sim 0.7-2.1{ }^{\circ} \mathrm{C}$ achieved in a recent multi-lake comparative analyses using the 1D-model GLM [27]. The MAEs (Table B1 of Supplementary Material S1) for the entire water column of $0.71{ }^{\circ} \mathrm{C}$ for Sihlsee and $0.65{ }^{\circ} \mathrm{C}$ for Upper Lake Zurich are within the range of $\sim 0.3-0.9^{\circ} \mathrm{C}$ that resulted from 70 previous applications of CE-QUAL-W2 [26]. RMSEs for dissolved oxygen are comparable to the value of $1.05 \mathrm{mg} \mathrm{L}^{-1}$ in a recent study on reducing thermal pollution downstream with the additional objective to avoid hypoxia [15], and again within the range typically achieved with CE-QUAL-W2 for similar applications $[26,28]$. The same is true for nutrient concentrations, where, for example, Deliman and Gerald [28] showed RMSEs of $570 \mu \mathrm{g} \mathrm{N} \mathrm{L}^{-1}$ for the sum of nitrate and nitrite and $40 \mu \mathrm{g} \mathrm{P} \mathrm{L}^{-1}$ for total phosphorus; and Smith et al. [29] presented RMSEs in the hypolimnion of $\leq 100 \mu \mathrm{g} \mathrm{N} \mathrm{L}{ }^{-1}$ for the sum of nitrate and nitrite and $\leq 16 \mu \mathrm{g} \mathrm{P} \mathrm{L}^{-1}$ for total phosphorus as well as RMSEs in the epilimnion of $\leq 40 \mu \mathrm{g} \mathrm{N} \mathrm{L}^{-1}$ and $\leq 7 \mu \mathrm{g} \mathrm{P} \mathrm{L}^{-1}$ for the sum of nitrate and nitrite and total phosphorus, respectively. RMSEs of the sum of nitrate and nitrite presented in two further studies, which both focussed on projecting the response to nutrient reduction scenarios, were $\sim 100 \mu \mathrm{g} \mathrm{N} \mathrm{L}^{-1}$ for both epi- and hypolimnion [22] and $\leq 590 \mu \mathrm{g} \mathrm{N} \mathrm{L}^{-1}$ [21] for the entire water column.

Table 2. Root mean square error (RMSE) of temperature, dissolved oxygen, the sum of nitrate and nitrite as well as total phosphorus computed for the entire water column, the epilimnion and the hypolimnion of Sihlsee and Upper Lake Zurich.

\begin{tabular}{|c|c|c|c|c|c|c|c|}
\hline & & \multicolumn{3}{|c|}{ Sihlsee } & \multicolumn{3}{|c|}{ Upper Lake Zurich } \\
\hline & & \multicolumn{3}{|c|}{ 2014-2015 } & \multicolumn{3}{|c|}{ 1998-2015 } \\
\hline Variable & Unit & $\begin{array}{c}\text { Entire } \\
\text { Water } \\
\text { Column }\end{array}$ & Epilimnion $^{1}$ & Hypolimnion ${ }^{2}$ & $\begin{array}{c}\text { Entire } \\
\text { Water } \\
\text { Column }\end{array}$ & Epilimnion $^{1}$ & Hypolimnion ${ }^{3}$ \\
\hline Temperature & {$\left[{ }^{\circ} \mathrm{C}\right]$} & 0.94 & 0.93 & 0.94 & 0.93 & 0.78 & 0.98 \\
\hline Dissolved oxygen & {$\left[\mathrm{mg} \mathrm{L}^{-1}\right]$} & 1.15 & 1.07 & 1.38 & 1.26 & 0.99 & 1.16 \\
\hline $\begin{array}{c}\text { Sum nitrate and } \\
\text { nitrite }\end{array}$ & {$\left[\mu \mathrm{g} \mathrm{N} \mathrm{L}^{-1}\right]$} & 76 & 69 & 89 & 114 & 142 & 114 \\
\hline Total phosphorus & {$\left[\mu \mathrm{g} \mathrm{P} \mathrm{L}^{-1}\right]$} & 4.45 & 2.74 & 6.51 & 4.13 & 3.90 & 3.96 \\
\hline
\end{tabular}

\subsection{Pumped-Storage Scenarios}

Here, we present the results of simulations corresponding to present PS operations, the largest PS extension scenario and two reference scenarios considering no PS flows.

The present PS scenario represents the current state, where water is withdrawn from the hypolimnion of Sihlsee for both generating electricity ( 135 MW installed capacity) and the residual flow to River Sihl. Water from Upper Lake Zurich is pumped up to Sihlsee ( 65 MW installed capacity) 
and discharged to its hypolimnion. At Upper Lake Zurich, intake and outlet of the PS hydropower plant are placed within the epilimnion.

The extended PS is operated with installed capacities of $525 \mathrm{MW}$ and $265 \mathrm{MW}$ for generating and pumping, respectively. The basic hourly dataset for this scenario was provided by the Swiss Federal Railways and considered monthly-averaged net inflows to Sihlsee. It was adapted to account for hourly instead of monthly mean natural inflows, to allow assessing the influence of floods and low flows (details are given in Section A.3 of Supplementary Material S1).

For the first reference scenario (NoPS) water is withdrawn from the hypolimnion through the present outlet of River Sihl's residual flow. The discharge of River Sihl downstream the dam is based on a regime analysis of observed outflows, before the dam was built (LIMNEX AG, 2016, personal communication), representing a near-natural effluent for River Sihl downstream of the dam.

For the second reference scenario (QNat), the discharge to River Sihl is similar to that of NoPS, but released from the epilimnion, where water is discharged over a weir (crest at $887.4 \mathrm{~m}$ a.s.l., of Figure A1 Supplementary Material S1). This outflow corresponds to the "theoretical" natural state of the lake, if the dam were of natural origin.

The current PS generating flow approximately equals the sum of inflows for Sihlsee, but contributes $<10 \%$ to the total inflows of Upper Lake Zurich (Table 1). The pumping flow accounts for $\sim 10 \%$ of the natural inflows at Sihlsee and for $\sim 1 \%$ at Upper Lake Zurich. Consequently, the impacts of the PS operations are much more important for Sihlsee, and we focus the discussion of the results on this reservoir. Results for Upper Lake Zurich are presented in Supplementary Material S1 (Section C).

\subsection{Aggregation of Results}

From the simulated temperatures and concentrations of dissolved oxygen and nutrients, we calculated means, minima and maxima of all years included in the studied period (1998-2012) for each day of the year. The simulations were aggregated separately for the epilimnion (represented by the uppermost $5 \mathrm{~m}$ of the water column) and the hypolimnion (represented by the lowermost $5 \mathrm{~m}$ of the water column). The differences between scenarios were calculated at every depth and then aggregated for either the epi- or the hypolimnion. The aggregation included the computation of mean and standard deviation for each season.

The durations of summer and inverse winter stratification were defined as the longest uninterrupted periods with temperature differences $>0.2{ }^{\circ} \mathrm{C}$ and $<-0.2{ }^{\circ} \mathrm{C}$ between the upper- and the lowermost layer. Schmidt stability was calculated according to Idso [30] for each day and its mean value was calculated for each month. Ice-on was defined as the first day in winter, when ice thickness at SEG38 was $>0 \mathrm{~m}$, and ice-off as the first day in spring without ice at SEG38.

\section{Results}

Figure 2 depicts the mean and extrema for temperature, dissolved oxygen and nutrients for all considered PS scenarios, and Figure 3 shows a boxplot of their seasonal differences between either one of the two reference scenarios QNat and NoPS or the extended PS scenario and the present PS scenario. In both figures, the results are presented separately for the epi- and the hypolimnion.

In summer and autumn (May-December), epilimnion temperatures of Sihlsee are $\sim 1.6^{\circ} \mathrm{C}$ lower in the reference scenario QNat compared to all other scenarios. Hypolimnion temperatures for QNat are reduced by up to $10-11^{\circ} \mathrm{C}$ in late August compared to the other scenarios. These large temperature differences result from hypolimnetic water withdrawal, which draws the thermocline and warmer epilimnion water downwards. This highlights the strong effect of deep water withdrawal on the temperature regime of Sihlsee. In contrast, the hypolimnion temperature differences between the extended and the present PS operation generally range within $\sim 3^{\circ} \mathrm{C}$, and those between the present PS operation and NoPS are $<1{ }^{\circ} \mathrm{C}$ for most of the summer. In both cases, the hypolimnion of Sihlsee is warmed during summer due to pumping of epilimnion water from Upper Lake Zurich. 
In winter and spring (December-May), epilimnetic temperatures are similar for all scenarios except for the extended PS scenario, where they increase by $\sim 1.6^{\circ} \mathrm{C}$. These differences are shaped by enhanced PS pumping flow during winter and result also in a significantly shortened ice-covered period (Figure $4 \mathrm{a}$ ) along with start and end dates of summer and inverse stratification, for the extended PS scenario. This further results in a decreasing ice thickness from $\sim 30-34 \mathrm{~cm}$ to $\sim 23 \mathrm{~cm}$ for the extended PS scenario (Figure 4c). Inverse stratification is also shortened by $\sim 50$ days (later start and earlier end) due to the pumping of comparably warm water from Upper Lake Zurich.

The deep water withdrawal of present PS, extended PS and NoPS reference scenarios affects stratification (Figure 4a) and water column stability (Figure 4b) accordingly. Summer stratification is prolonged for QNat by $\sim 40-50$ days since water temperatures are much cooler for this scenario in autumn and more time is needed to cool the water column sufficiently to initiate mixing. For extended PS, summer stratification is prolonged by $\sim 10-15$ days, caused by earlier stratification start due to earlier ice-off (Figure 4a).

Schmidt stability is for most months smallest in the extended PS scenario (Figure 4b). Thus, enhanced PS pumping flow generally decreases water column stability. In the simulations this leads occasionally (three times in 12 years) to temperature differences $<0.5^{\circ} \mathrm{C}$ between the upper- and lowermost layer, and, thus, strong wind events can initiate almost complete mixing of the water column in summer. This does not occur in the near-natural reference scenario QNat. The other three scenarios show major differences from August to October, where Schmidt stability is decreased by factors of up to $\sim 3.3$ compared to the reference scenario QNat.

Dissolved oxygen concentrations in the epilimnion are mainly driven by equilibration with the atmosphere and primary production and do not differ much between the scenarios, only the shorter ice-covered period slightly raises concentrations in spring for the extended PS scenario. Conversely, large differences arise in the hypolimnion, where the prolonged stratification in the reference scenarios QNat increases the time available for oxygen depletion due to the decomposition of organic matter. This leads to maximum differences of $\sim 8 \mathrm{mg} \mathrm{L}^{-1}$ in late October when hypolimnetic oxygen concentrations reach their minimum in QNat, but are already partially replenished by seasonal mixing in the other scenarios. In addition, PS introduces oxygen-rich water from the epilimnion of Upper Lake Zurich to the hypolimnion of Sihlsee, counteracting oxygen depletion during both summer stratification and inverse winter stratification, which is particularly the case for the extended PS scenario (Figure 3). Following the Swiss Water Protection Ordinance [31], dissolved oxygen concentrations in lakes should always exceed a threshold of $4 \mathrm{mg} \mathrm{L}^{-1}$. In the near-natural reference scenario QNat, simulated concentrations fall below this threshold every year, on average during $\sim 90$ days. This value is reduced to $\sim 33$ days (in 14 out of 15 years) for the reference NoPS, and $\sim 22$ days (11 years) for the present PS scenario. For the extended PS scenario, hypolimnetic dissolved oxygen concentrations below $4 \mathrm{mg} \mathrm{L}^{-1}$ were simulated only in one year for an uninterrupted period of $\sim 3$ days, which is still less than for the other scenarios in that specific year.

Nutrient concentrations are also affected by both the exchange of water in the PS scenarios and the changes in stratification due to the withdrawal depth. The sum of nitrate and nitrite concentrations is increased by a factor of $\sim 1.2-4$ in the extended PS scenario, as the prevailing concentrations are higher by factor of $\sim 3$ in Upper Lake Zurich compared to Sihlsee. Similarly, phosphate concentrations increase during winter (November-April) by $\sim 2-6 \mu \mathrm{g} \mathrm{P} \mathrm{L}{ }^{-1}$. For present PS, these effects are much smaller, as the PS pumping flow is only $5 \%$ of that in the extended PS. The prolonged stratification in the reference scenario QNat allows more time for the accumulation of nutrients in the hypolimnion from mineralization at the sediment surface. Until late October, nutrient concentrations are increased by up to $\sim 80 \mu \mathrm{g} \mathrm{N} \mathrm{L}{ }^{-1}$ and $\sim 7 \mu \mathrm{g} \mathrm{P} \mathrm{L}{ }^{-1}$ for the sum of nitrate and nitrite and phosphate, respectively, compared to the present PS scenario. Seasonal mixing propagates the effects on nutrient concentrations from the hypo- to the epilimnion. Thus, concentrations are raised in the reference scenario QNat from April to December by up to $2.3 \mu \mathrm{g} \mathrm{P} \mathrm{L}{ }^{-1}$ and $21 \mu \mathrm{g} \mathrm{N} \mathrm{L}-1$ for phosphate and the sum of nitrate and nitrite, respectively. 


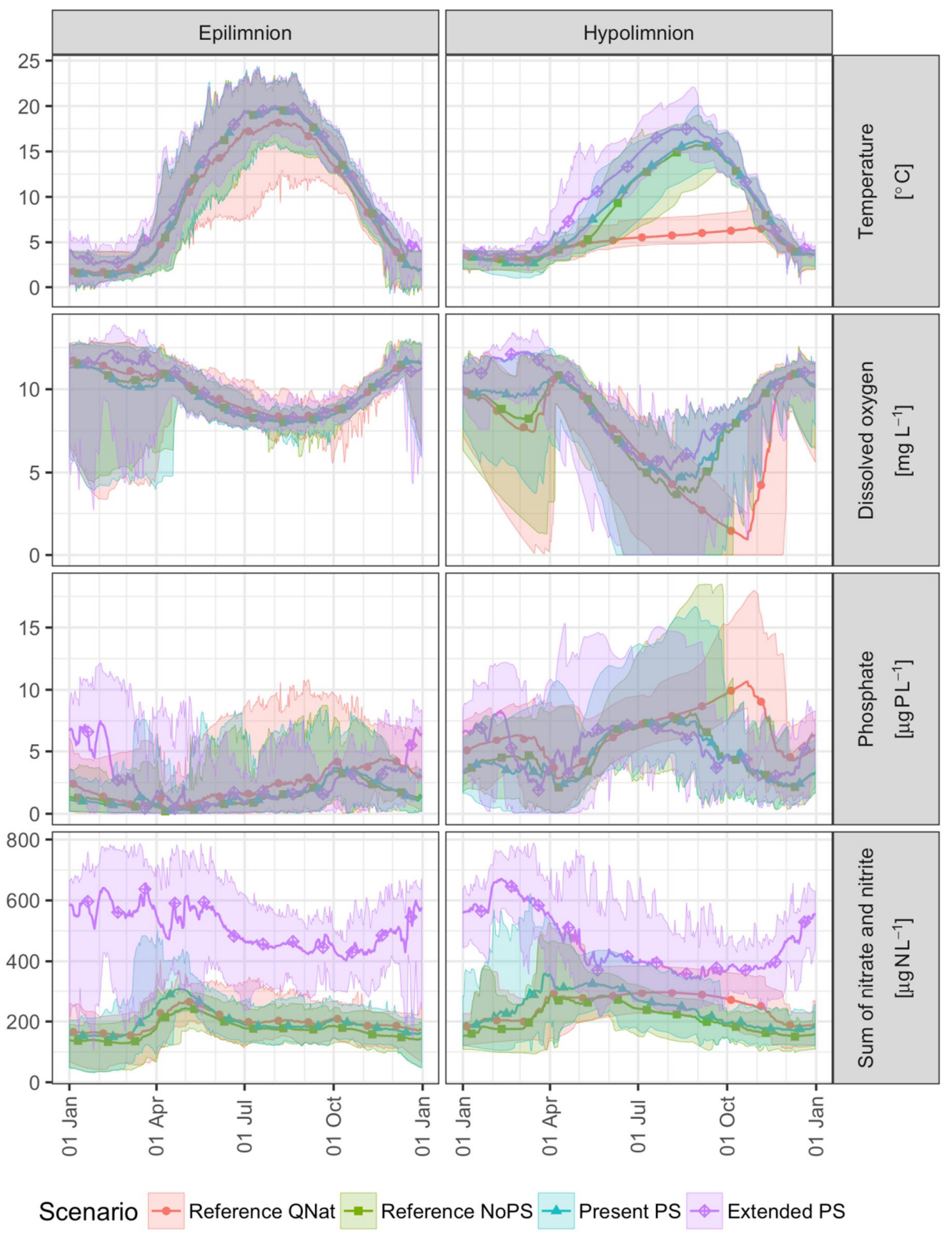

Figure 2. Mean (lines with markers) and range of minima and maxima (shaded areas) of simulated temperatures $\left({ }^{\circ} \mathrm{C}\right)$ and concentrations of dissolved oxygen $\left(\mathrm{mg} \mathrm{L}^{-1}\right)$, phosphate $\left(\mu \mathrm{P} \mathrm{L} \mathrm{L}^{-1}\right)$ and the sum of nitrate and nitrite $\left(\mu \mathrm{g} \mathrm{N} \mathrm{L}{ }^{-1}\right)$ for the two reference scenarios QNat (red) and NoPS (olive-green), the present (turquoise) and the extended PS (violet) scenarios in the epilimnion (uppermost $5 \mathrm{~m}$ of the water column) and the hypolimnion (lowermost $5 \mathrm{~m}$ of the water column) of Sihlsee. 


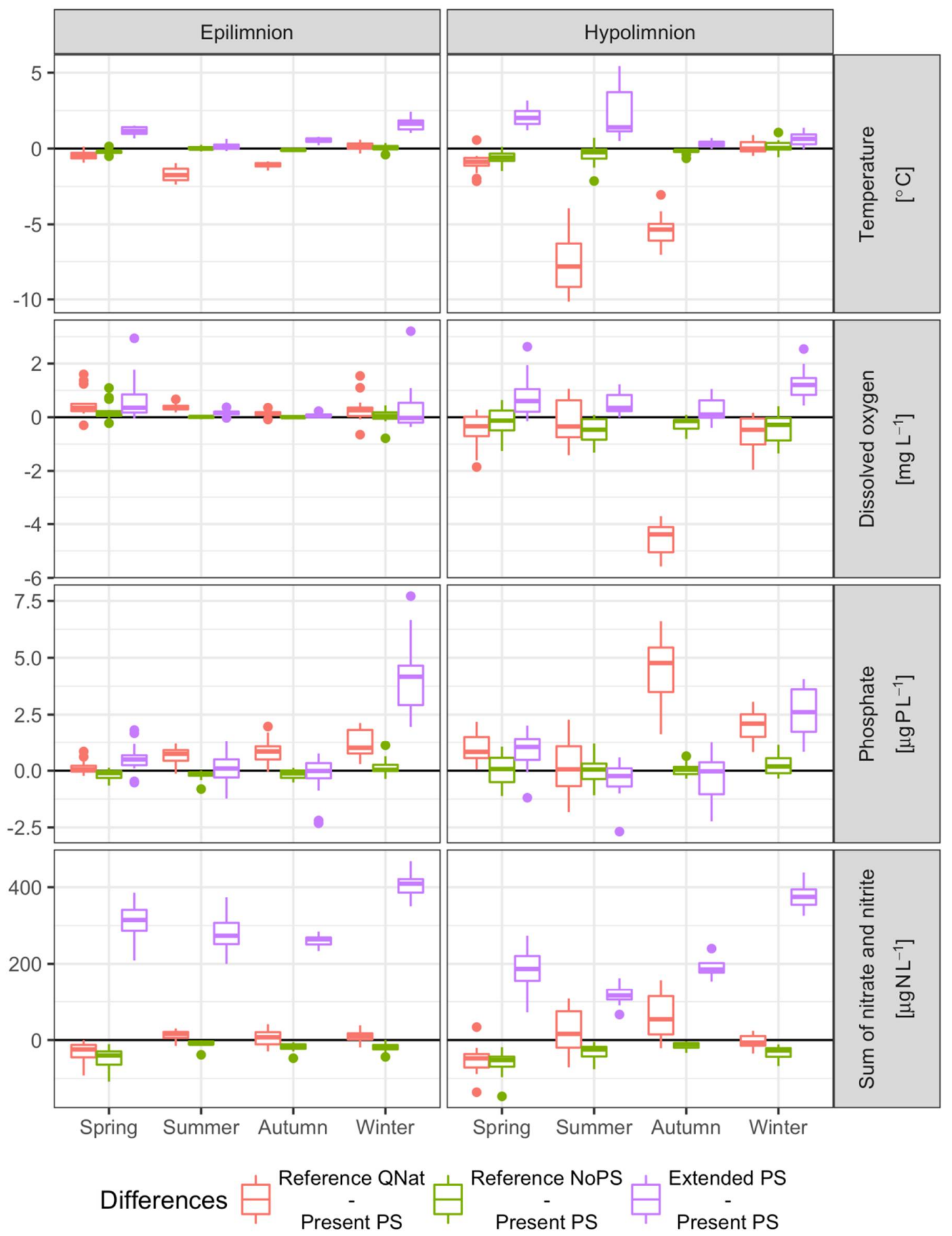

Figure 3. Boxplot of differences in either one of the two reference scenarios NoPS and QNat or the extended PS scenario to the present PS scenario of temperature $\left({ }^{\circ} \mathrm{C}\right)$ and concentrations of dissolved oxygen $\left(\mathrm{mg} \mathrm{L}^{-1}\right)$, phosphate $\left(\mu \mathrm{g} \mathrm{P} \mathrm{L}^{-1}\right)$ and the sum of nitrate and nitrite $\left(\mu \mathrm{g} \mathrm{N} \mathrm{L}^{-1}\right)$ at Sihlsee. Points show outliers; values were aggregated seasonally for each year before plotting (winter: December-February; spring: March-May; summer: June-August; and autumn: September-November). 
(a)

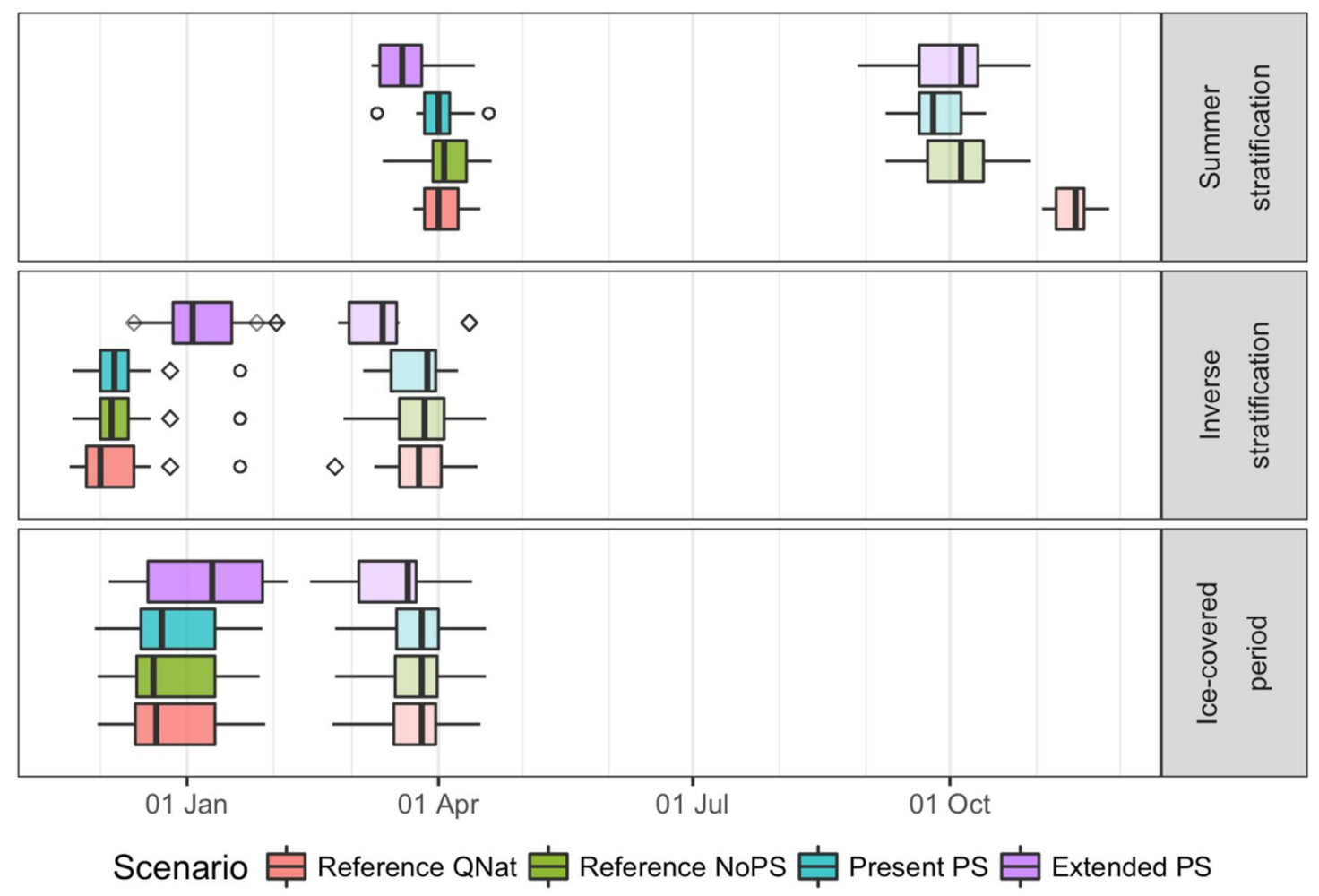

(b)

(c)
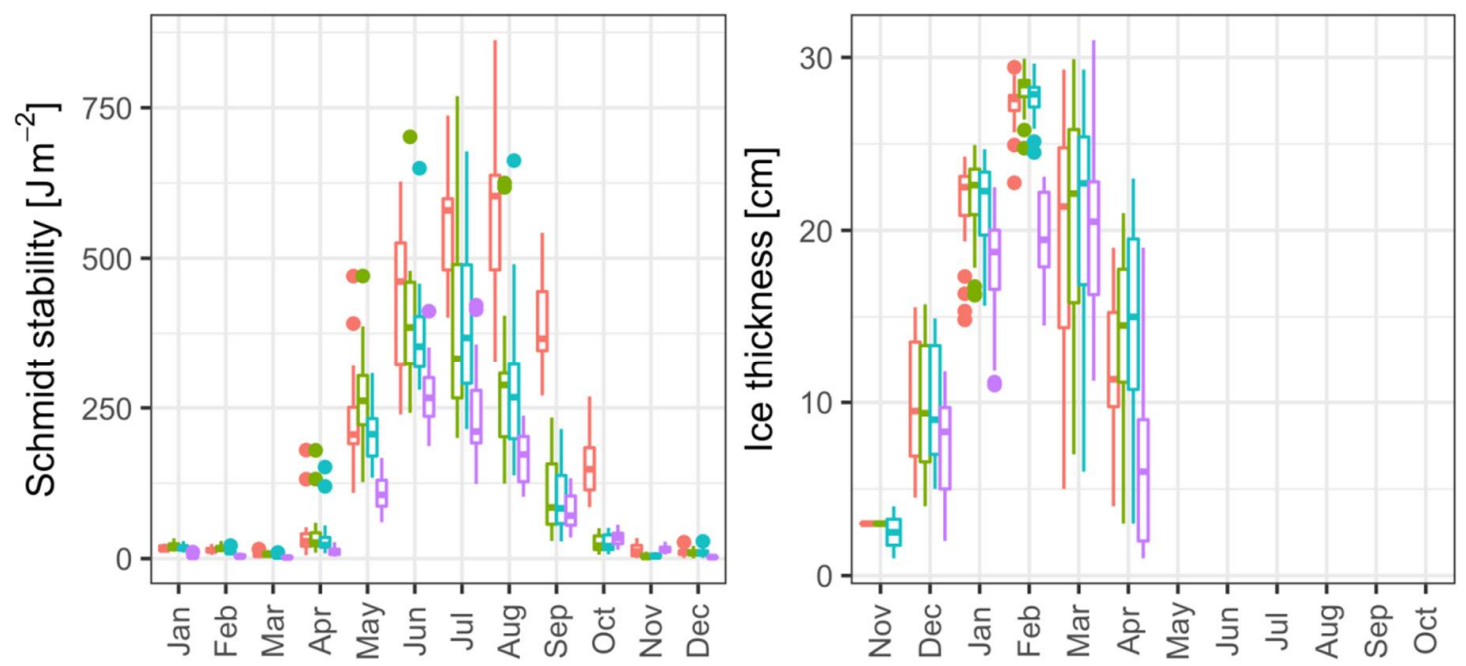

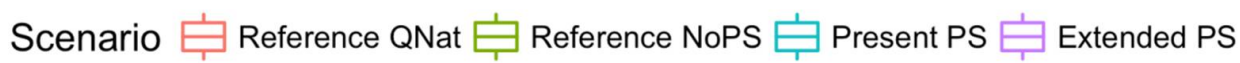

Figure 4. Boxplots for the two reference scenario NoPS and QNat, the present PS and the extended PS scenario at Sihlsee: (a) start and end of summer or inverse stratification as well as ice-on and ice-off; (b) monthly mean of Schmidt stability $\left(\mathrm{J} \mathrm{m}^{-2}\right)$; and (c) monthly mean of ice thickness (cm). Points show outliers of start (circles) and end (squares) of summer or inverse stratification as well as ice-covered period.

\section{Discussion}

At Sihlsee, extended PS operation is projected to result, compared to the present PS, in: (a) an increase of hypolimnion temperature by $\sim 2{ }^{\circ} \mathrm{C}$ during summer due to pumping surface water from 
Upper Lake Zurich; (b) warming of surface water by $\sim 1.6^{\circ} \mathrm{C}$ during winter and spring mostly due to enhanced mixing; (c) later development of inverse stratification by 1.5 month; (d) a delay of overturn in spring by $\sim 2$ weeks; (e) earlier ice-off by $\sim 1$ month and $~ 30 \%$ thinner ice; (f) increased dissolved oxygen concentrations in the hypolimnion; and $(\mathrm{g})$ increased nutrient concentrations originating from higher concentrations in the lower lake. The sum of nitrate and nitrite concentrations in winter and spring are decreasing at Upper Lake Zurich for the same reasons as they increase in Sihlsee. However, effects on Upper Lake Zurich are much less pronounced due to its larger volume and higher natural discharges. Local effects of PS operation in the vicinity of the intake/outlet of the PS hydropower plant are expected to be higher, but their analysis would require 3D simulations in the near field [32].

Besides these effects of PS operations, the simulations highlighted the importance of the withdrawal depth in Sihlsee. If located in the hypolimnion (reference scenario NoPS), the differences to the present PS scenario are minor. Conversely, large effects result if the outlet is placed within the epilimnion (reference scenario QNat) with: (a) hypolimnion temperatures decreasing to commonly observed values of natural lakes in that region; (b) a consequent reduction of epilimnion temperature; (c) delayed summer stratification by $\sim 1.5$ months; (d) therefore, reduced dissolved oxygen concentrations; (e) increased phosphate concentrations; and (f) higher sum of nitrate and nitrite concentrations due to delayed seasonal mixing.

These findings can be put into the context of previous modeling studies on pumped-storage hydropower facilities. Additional information about the systems investigated in these studies is given in Supplementary Material S1 (Section D).

Bonalumi et al. [23] showed that both water bodies connected by a PS scheme would mostly be warmed. In autumn, $50 \%$ of this warming in the upper hypolimnion of the lower lake would be due to frictional warming of the PS flows. This effect is not as relevant for the case of Sihlsee and Upper Lake Zurich due to the much smaller head. In Lake Oconee, the water column was completely mixed in summer after the introduction of PS operation, whereas before temperature differences between epi- and hypolimnion had ranged between 5 and $13{ }^{\circ} \mathrm{C}$ [33]. This is comparable to the strong reduction of Schmidt stability in Sihlsee in the extended PS scenario, but the extent of PS operations is insufficient to completely homogenize it. At Twin Lakes, the PS operation reduced the residence time from 314 to 176 days, resulted in cooling of both basins of Twin Lakes, and weakened stratification [34]. Anderson [18] concluded that the timing of stratification at Lake Elsinore would not be affected by PS, although stratification, expressed as the temperature difference between surface and bottom waters, would be weakened by $1.2{ }^{\circ} \mathrm{C}$ in late May. Our findings confirm that summer stratification can be weakened by PS operation. Our results also suggest, in contrast to Anderson [18] and Bermúdez et al. [19], that the timing of stratification can be affected by PS, particularly that of inverse stratification. Regarding the PS impact on temperature, our results indicate a warming of the hypolimnion, which is contrary to the findings of USBR [34], but similar to those of Bonalumi et al. [23] and Potter et al. [33].

Overall, the results of our study showed that the effects of the water exchange due to PS operations, even for extended PS, are small compared to those caused by deep water withdrawal. Similarly, for the drinking water reservoir Grosse Dhuenn [15], selective withdrawal was shown to move the thermocline upwards, increase differences between water temperature of the epi- and hypolimnion, and thus strengthen thermal stratification, when being compared to bottom water withdrawal. These observations highlight the importance of withdrawal depth as a crucial parameter in the design of PS hydropower plants for reducing ecological impacts. However, water temperature and stratification are not the only parameters to be considered for optimizing withdrawal depth, e.g., concentrations of glacial particles might necessitate an intake/outlet placement in the hypolimnion [23].

In the simulations of Bonalumi et al. [23], PS operations were projected to significantly reduce ice cover duration. However, due to a lack of observational data for calibrating the model, this effect could not be reliably quantified. With a modified parameterization of CE-QUAL-W2, we were able 
to reliably reproduce ice cover duration (Figure B4 of Supplementary Material S1). With this model, we could show that extended PS would strongly reduce ice thickness and ice-cover duration in Sihlsee.

Water quality parameters, such as dissolved oxygen, and nutrient concentrations, are affected by PS operations through two different mechanisms: exchange of water masses, and indirect effects due to changes in mixing and stratification. The importance of the first mechanism scales with the ratio of the exchanged water masses and the volumes of the basins as shown for example for the sum of nitrate and nitrite in Sihlsee above. Similarly, Bonalumi et al. [23] found inorganic suspended solid concentrations to decrease in the upper reservoir and to increase in the lower lake. At Twin Lakes, inorganic suspended solid concentrations decreased by $40 \mathrm{mg} \mathrm{L}^{-1}$ when PS operations were introduced, which was also linked to dilution [34].

Changes in thermal stratification affect water quality in various ways. At Sihlsee, the bottom water withdrawal leads to weaker stratification, and reduces its duration by $>1$ month. This further affects hypolimnetic dissolved oxygen concentrations: due to less time being available to reduce dissolved oxygen to low levels, more dissolved oxygen being resupplied by mixing through the weaker thermocline, and additional supply of dissolved oxygen as river inflows plunge more easily through a weaker density gradient. Consequently, dissolved oxygen concentrations fall below the legal target of $4 \mathrm{mg} \mathrm{L}^{-1}$ in a much smaller volume and during a shorter period. This is in line with the findings of Weber et al. [15] and Anderson et al. [35] that the hypolimnion of a reservoir is more oxygenated when water is withdrawn at the bottom. Likewise, at Twin Lakes, the PS operation seems to have resulted in slight aeration of the hypolimnion, which was considered beneficial, as it increased habitat volume of fish [34].

According to Anderson et al. [35], phosphorus concentrations decrease when water is withdrawn from the hypolimnion. This is in accordance with our findings, as we found additional accumulation in autumn induced by intensified stratification for the reference scenario QNat. Nevertheless, PS impacts on nutrient concentrations are site-specific.

Our projections for effects of PS and deep water withdrawal on temperature and stratification are robust, since they are large compared to the uncertainty of the model, and supported by an extensive data set of temperature for model calibration. The required correction of the water balance and the lack of information to divide the outflow into surface outflow and deep water withdrawal, in the case of flood events, might somewhat affect mixing patterns for these flood events, but should not change the overall picture. The projected effects on water quality include a higher uncertainty, which is due to limited availability of hydrological and water quality forcing of inflows. Nevertheless, the projected changes in water quality yield a coherent picture of the effects of water exchange and those due to changes in thermal stratification.

When recommissioning a PS hydropower plant, a reference state needs to be defined for the environmental impact assessment. For natural lakes, this is the scenario which does not include any artificial PS flows. However, for reservoirs such as Sihlsee, this scenario is mostly a matter of definition: it might be described as the natural state without a lake, where the original river stretch needs to be analyzed; it might also be an artificial state, with the reservoir remaining due to its multiple other purposes, but PS operations being removed. The simulated effects for the reference scenarios NoPS and QNat highlight that the estimated environmental impacts can depend heavily on the choice of the reference scenario. Thus, we see a need for guidelines to define such reference scenarios in the context of assessing environmental impacts of increased development or the extension of PS hydropower plants.

\section{Conclusions}

Previous studies have shown, by both pre- and post-operational observations and modeling, that PS operations can have significant impacts on temperature and thermal stratification in the connected water bodies. With the present study, we aimed at extending this assessment to indicators of water quality (oxygen and nutrient concentrations) as well as the duration and extent of ice cover. 
For this purpose, we projected the effects of a PS extension scenario for the case of Etzelwerk, using a directly coupled hydrodynamic and water quality model for the two connected water bodies. The results showed that PS extension would increase water temperatures in the hypolimnion of the upper reservoir by $\sim 2{ }^{\circ} \mathrm{C}$ in summer. The model also projected a significant reduction of the duration and thickness of ice cover due to the PS operations. Additionally, the increased PS pumping flow would raise the nutrient concentrations in the upper reservoir and increase dissolved oxygen availability in its hypolimnion. These effects of PS operation on lake water quality are not easily transferable to other systems, as they depend on the natural, site-specific water quality. In tendency, however, PS supports a decrease of the strength and duration of stratification with correlated effects on dissolved oxygen and nutrients.

Furthermore, we aimed at disentangling the effects of PS operation and deep water withdrawal, which has up to now not been quantified in the context of PS operations. This was achieved by analyzing two reference scenarios: (i) a scenario without hydropower but with deep water withdrawal from the upper reservoir; and (ii) a "quasi-natural" scenario with surface outflow. The scenario without hydropower showed comparably minor differences to the present PS operation. Conversely, the "quasi-natural" scenario highlighted a large effect of the withdrawal depth on the upper reservoir. Compared to the present state, the surface outflow decreased hypolimnetic water temperature by up to $\sim 10{ }^{\circ} \mathrm{C}$, and, accordingly, intensified stratification, and reduced dissolved oxygen concentrations. Thus, we can claim that at Etzelwerk the impacts of water withdrawal in the hypolimnion are more crucial than those of PS operations, especially for the present, but also for the extended PS operation. This also underlines the importance of the location of the PS intake/outlet. Consequently, withdrawal depth in the reference state defines relevant implications for the estimated environmental impacts of a PS scheme. For management purposes, it is, therefore, important to have clear guidelines for defining a reference state as a base scenario for assessing the environmental impacts of increased development or extension of PS hydropower plants. We, thus, recommend for future projects to separately analyze effects due to withdrawal depth and those due to PS operation. Although the effects on the natural lake were small in the present study, these need to be cautiously investigated at any other site.

Supplementary Materials: The following are available online at http:/ /www.mdpi.com/2071-1050/10/6/1968/ s1. File S1: "Effects of lake-reservoir pumped-storage operations on temperature and water quality".

Author Contributions: Conceptualization, U.G.K., M.S., and A.W.; Methodology, U.G.K. and M.S.; Software, U.G.K.; Validation, U.G.K. and M.S.; Formal Analysis, U.G.K. and M.S.; Investigation, U.G.K.; Data Curation, U.G.K.; Writing-Original Draft Preparation, U.G.K.; Writing-Review and Editing, M.S. and A.W.; Visualization, U.G.K.; Supervision, M.S., and A.W.; Project Administration, M.S.; and Funding Acquisition, M.S.

Acknowledgments: We want to thank P. Meier for his insights, and M. Schurter, M. Plüss, P. Kathriner and the employees at Etzelwerk for the assistance with fieldwork and lab analysis. We additionally thank MeteoSwiss, FOEN, the Cantonal Environmental Agencies of Schwyz and St. Gallen, WVZ, WSL and Limnex AG for their cooperation and data supply. Funding was provided by the Swiss Federal Railways (SBB AG).

Conflicts of Interest: The authors declare no conflict of interest.

\section{References}

1. Barbour, E.; Grant Wilson, I.A.; Radcliffe, J.; Ding, Y.; Li, Y. A review of pumped hydro energy storage development in significant international electricity markets. Renew. Sustain. Energy Rev. 2016, 61, 421-432. [CrossRef]

2. EU Commission. Energy Roadmap 2050; COM(2011) 885; EU Commission: Brussels, Belgium, 2011.

3. REN21. Renewables 2017 Global Status Report; REN21 Secretariat: Paris, France, 2017.

4. Evans, A.; Strezov, V.; Evans, T.J. Assessment of utility energy storage options for increased renewable energy penetration. Renew. Sustain. Energy Rev. 2012, 16, 4141-4147. [CrossRef]

5. Ibrahim, H.; Ilinca, A.; Perron, J. Energy storage systems-Characteristics and comparisons. Renew. Sustain. Energy Rev. 2008, 12, 1221-1250. [CrossRef]

6. Rehman, S.; Al-Hadhrami, L.M.; Alam, M.M. Pumped hydro energy storage system: A technological review. Renew. Sustain. Energy Rev. 2015, 44, 586-598. [CrossRef] 
7. Deane, J.P.; Gallachòir, B.Ò.; McKeogh, E. Techno-economic review of existing and new pumped hydro energy storage plant. Renew. Sustain. Energy Rev. 2010, 14, 1293-1302. [CrossRef]

8. Bonalumi, M.; Anselmetti, F.S.; Kägi, R.; Wüest, A. Particle dynamics in high-Alpine proglacial reservoirs modified by pumped-storage operation. Water Resour. Res. 2011, 47, W09523. [CrossRef]

9. Anderson, M.A. Technical Analysis of the Potential Water Quality Impacts of LEAPS on Lake Elsinore; Department of Environmental Sciences, University of California Riverside: Riverside, CA, USA, 2006.

10. Liu, L.X.; Wu, J.C. Research on ice formation during winter operation for a pumped storage station. In Ice in Surface Waters; Shen, H.T., Ed.; A. A. Balkema: Rotterdam, The Netherlands, 1999; pp. 753-759.

11. Solvang, E.; Harby, A.; Killingtveit, Å. Increasing Balance Power Capacity in Norwegian Hydroelectric Power Stations; SINTEF Energy Report TR A7126; SINTEF Energi: Trondheim, Norway, 2012.

12. Bell, E.; Kramer, S.; Zajanc, D.; Aspittle, J. Salmonid fry stranding mortality associated with daily water level fluctuations in Trail Bridge Reservoir, Oregon. N. Am. J. Fish. Manag. 2008, 28, 1515-1528. [CrossRef]

13. Hauck, F.R.; Edson, Q.A. Pumped storage: Its significance as an energy source and some biological ramifications. Trans. Am. Fish. Soc. 1976, 105, 158-164. [CrossRef]

14. Harby, A.; Sauterleute, J.; Korpås, M.; Killingtveit, Å.; Solvang, E.; Nielsen, T. Pumped Storage Hydropower. In Transition to Renewable Energy Systems; Stolten, D., Scherer, V., Eds.; Wiley-VCH Verlag GmbH \& Co. KGaA: Weinheim, Germany, 2013; pp. 597-618.

15. Weber, M.; Rinke, K.; Hipsey, M.R.; Boehrer, B. Optimizing withdrawal from drinking water reservoirs to reduce downstream temperature pollution and reservoir hypoxia. J. Environ. Manag. 2017, 197, 96-105. [CrossRef] [PubMed]

16. Romero, J.R.; Antenucci, J.P.; Imberger, J. One- and three-dimensional biogeochemical simulations of two differing reservoirs. Ecol. Model. 2004, 174, 143-160. [CrossRef]

17. Gebre, S.; Boissy, T.; Alfredsen, K. Sensitivity to climate change of the thermal structure and ice cover regime of three hydropower reservoirs. J. Hydrol. 2014, 510, 208-227. [CrossRef]

18. Anderson, M.A. Influence of pumped-storage hydroelectric plant operation on a shallow polymictic lake: Predictions from 3-D hydrodynamic modeling. Lake Reserv. Manag. 2010, 26, 1-13. [CrossRef]

19. Bermúdez, M.; Cea, L.; Puertas, J.; Rodríguez, N.; Baztán, J. Numerical Modeling of the Impact of a Pumped-Storage Hydroelectric Power Plant on the Reservoirs' Thermal Stratification Structure: A Case Study in NW Spain. Environ. Model. Assess. 2018, 23, 71-85. [CrossRef]

20. Van der Linden, L.; Daly, R.I.; Burch, M.D. Suitability of a Coupled Hydrodynamic Water Quality Model to Predict Changes in Water Quality from Altered Meteorological Boundary Conditions. Water 2015, 7, 348-361. [CrossRef]

21. Kuo, J.-T.; Lung, W.-S.; Yang, C.-P.; Liu, W.-C.; Yang, M.-D.; Tang, T.-S. Eutrophication modelling of reservoirs in Taiwan. Environ. Model. Softw. 2006, 21, 829-844. [CrossRef]

22. Liu, W.-C.; Chen, W.-B.; Kimura, N. Impact of phosphorus load reduction on water quality in a stratified reservoir-eutrophication modeling study. Environ. Monit. Assess. 2009, 159, 393-406. [CrossRef] [PubMed]

23. Bonalumi, M.; Anselmetti, F.S.; Wüest, A.; Schmid, M. Modeling of temperature and turbidity in a natural lake and a reservoir connected by pumped-storage operations. Water Resour. Res. 2012, 48, WR01184. [CrossRef]

24. Hirsch, P.E.; Eloranta, A.P.; Amundsen, P.-A.; Brabrand, Å.; Charmasson, J.; Helland, I.P.; Power, M.; Sánchez-Hernández, J.; Sandlund, O.T.; Sauterleute, J.F.; et al. Effects of water level regulation in alpine hydropower reservoirs: An ecosystem perspective with a special emphasis on fish. Hydrobiologia 2017, 794, 287-301. [CrossRef]

25. Bellmore, R.J.; Duda, J.J.; Craig, L.S.; Greene, S.L.; Torgersen, C.E.; Collins, M.J.; Vittum, K. Status and trends of dam removal research in the United States. Wiley Interdiscip. Rev. Water 2017, 4, e1164. [CrossRef]

26. Cole, T.M.; Wells, S.A. CE-QUAL-W2: A Two-Dimensional, Laterally Averaged, Hydrodynamic and Water Quality Model, Version 3.71. User Manual; Department of Civil and Environmental Engineering, Portland State University: Portland, OR, USA, 2013.

27. Bruce, L.C.; Frassl, M.A.; Arhonditsis, G.B.; Gal, G.; Hamilton, D.P.; Hanson, P.C.; Hetherington, A.L.; Melack, J.M.; Read, J.S.; Rinke, K.; et al. A multi-lake comparative analysis of the General Lake Model (GLM): Stress-testing across a global observatory network. Environ. Model. Softw. 2018, 102, 274-291. [CrossRef] 
28. Deliman, P.N.; Gerald, J.A. Application of the Two-Dimensional Hydrothermal and Water Quality Model, CE-QUAL-W2, to the Chesapeake Bay-Conowingo Reservoir. Lake Reserv. Manag. 2002, 18, 10-19. [CrossRef]

29. Smith, E.A.; Kiesling, R.L.; Galloway, J.M.; Ziegeweid, J.R. Water Quality and Algal Community Dynamics of Three Deepwater Lakes in Minnesota Utilizing CE-QUAL-W2 Models; Scientific Investigations Report 2014-5066; US Geological Survey: Reston, VA, USA, 2014; p. 73.

30. Idso, S.B. On the concept of lake stability. Limnol. Oceanogr. 1973, 18, 681-683. [CrossRef]

31. Der Schweizerische Bundesrat. Gewässerschutzverordnung vom 28. Oktober 1998 (GSchV); SR 814.201; Der Schweizerische Bundesrat: Bern, Switzerland, 1998.

32. Müller, M.; De Cesare, G.; Schleiss, A.J. Flow field in a reservoir subject to pumped-storage operation-In situ measurement and numerical modeling. J. Appl. Water Eng. Res. 2018, 6, 109-124. [CrossRef]

33. Potter, D.U.; Stevens, M.P.; Meyer, J.L. Changes in physical and chemical variables in a new reservoir due to pumped storage operations. J. Am. Water Resour. Assoc. 1982, 18, 627-633. [CrossRef]

34. US Bureau of Reclamation (USBR). Aquatic Ecology Studies of Twin Lakes, Colorado, 1971-1986: Effects of a Pumped-Storage Hydroelectric Project on a Pair of Montane Lakes; USBR: Denver, CO, USA, 1993.

35. Anderson, M.A.; Komor, A.; Ikehata, K. Flow routing with bottom withdrawal to improve water quality in Walnut Canyon Reservoir, California. Lake Reserv. Manag. 2014, 30, 131-142. [CrossRef]

(C) 2018 by the authors. Licensee MDPI, Basel, Switzerland. This article is an open access article distributed under the terms and conditions of the Creative Commons Attribution (CC BY) license (http://creativecommons.org/licenses/by/4.0/). 